\title{
Improvement of Resistance to Sclerotinia Crown and Stem Rot of Alfalfa through Phenotypic Recurrent Selection
}

\author{
Michio KANBE ${ }^{1 *}$, Yuko MIZUKAMI ${ }^{1}$ and Fumihiro FUJIMOTO ${ }^{2}$ \\ Department of Pasture Plant Breeding, National Institute of Livestock and Grassland Science \\ (Nishinasuno, Tochigi 329-2793, Japan)
}

\begin{abstract}
Breeding of alfalfa (Medicago sativa L.) for resistance to sclerotinia crown and stem rot (SCR, causal agent: Sclerotinia trifoliorum Eriks.), which is a serious disease in Japan, was initiated in 1983. Increase of resistance to this disease has been examined following repeated selection of surviving plants from artificially inoculated field plots to the 9th generation. The strains selected for SCR resistance showed a higher resistance than Natsuwakaba and Tachiwakaba which were used as breeding materials and control cultivars. The effectiveness of selection based on the survival rate of the progenies increased gradually as generations in which the recurrent selection was performed advanced. Realized heritability was low in the 1 st and 2 nd generations in which selection was performed but was high in the 3rd to 9th generations. It is considered that the selection effect on the SCR resistance was enhanced in the subsequent generations. The results of these studies may indicate that recurrent selection is effective for the accumulation of resistance genes with minor polygenic effect, especially in the case of breeding work for the improvement of characters, which had been considered almost impossible by short-term selection trials.
\end{abstract}

Discipline: Plant breeding

Additional key words: Medicago sativa, Sclerotinia trifoliorum, realized heritability

\section{Introduction}

Sclerotinia crown and stem rot (SCR) is one of the major constraints on stand establishment in alfalfa and other legumes in the northern part of Europe, humid zone of America and all over Japan, especially in areas with heavy snow. Alfalfa plants of all ages are susceptible to this disease but the damage is most severe at the seedling stage under cool and moist conditions. The damage may be extensive in late winter and early spring following the fall seeding of alfalfa ${ }^{2}$. Breeding of cultivars resistant to SCR was considered to be difficult because of the nonspecific character of the host-pathogen relationship reported in several pathological and breeding studies ${ }^{10,15}$. However, differences in the degree of disease severity were observed among alfalfa cultivars under artificial inoculation in the test field of Aichi Agricultural
Research Center (AARC) which is located in the warmer region of Japan. It was suggested that the inoculation method which employed hardening under natural conditions may enable to evaluate the resistance to $\mathrm{SCR}^{8}$. We observed that the growth conditions for the seedling test were optimum at $16^{\circ} \mathrm{C}$ under a $9 \mathrm{~h}$ day-length to reveal significant differences among the cultivars ${ }^{9}$. The nondormant cultivars showed a high susceptibility to the disease, whereas cultivars of the Flamande type were found to be more resistant than the others ${ }^{8)}$. Several other authors have observed differences among alfalfa and red clover cultivars in the damage caused by the occurrence of $\mathrm{SCR}^{1,13)}$. Trials to select resistant strains have been reported recently ${ }^{11,12)}$. We have initiated breeding work for resistance of alfalfa to SCR since 1983, and studies based on long-term selection for SCR resistance have been carried out in artificially inoculated field plots. In this paper, we report on the accumulated effects obtained

\footnotetext{
Present address:

${ }^{1}$ Aichi Agricultural Research Center (Nagakute, Aichi 480-1193, Japan)

${ }^{2}$ Gifu Keizai University (Kitagata, Gifu 503-8550, Japan)

*Corresponding author: fax +81-561-63-0815; e-mail m-kanbe@agri-rc.pref.aichi.jp

Received 4 December 2000; accepted 25 April 2001.
} 
in continued selection, and important implications for the breeding work. The estimation of heritability of the SCR resistance is also presented.

\section{Experimental procedures}

The following 10 cultivars and strains were used as the original population for SCR selection: Natsuwakaba, Tachiwakaba, LR43112-7, CRSY541-1, CR488-3, Everest, Derby, Lutece, Furez 507 and Delta. Selection of surviving plants was repeated for 9 generations in artificially inoculated fields. The selection method for each generation consisted basically of mass selection (Table 1).

Evaluation of resistance of each selected generation was carried out in 2 trials at the National Institute of Livestock and Grassland Science (NILGS) and AARC.

Evaluation 1: The strains from the 1st to 5th generations and 14 strains and cultivars were sown on August 23 and transplanted to the field on October 2, 1989 at NILGS. They were inoculated with mycelium from cultures of $S$. trifoliorum on April 11 at the base of the plants, and covered with a cheese cloth ( $85 \%$ shade) for 7 days.

Evaluation 2: The strains from the 5th to 9th generations were sown on September 29 and thinned in early November, 1994 at AARC. They were inoculated with $S$. trifoliorum by the same method on December 16 . The numbers of surviving plants 3 and 4 months after the inoculation were counted.

\section{Results}

Evaluation 1: Almost all the leaves and stems of alfalfa had rotted 2 weeks after the inoculation with $S$. tri- foliorum. Regrowth of the surviving plants was observed at 3 stages 18, 33 and 86 days after inoculation. The number of regrowing plants increased gradually for 3 months (Table 2). In the first observation, most of the cultivars did not show any evidence of regrowth. In the second observation on May 14, all the strains and cultivars displayed signs of regrowth and the survival rate of 3 selected strains was higher than that of Natsuwakaba by $15 \%$. There were highly significant differences among the selected strain groups and the commercial cultivars in the percentage of plants which had survived on July 6 . All the strains of the SR group (selected strains for SCR resistance) showed a higher percentage of survival than Tachiwakaba, the control cultivar. The highest survival rate of $57.6 \%$ was recorded in the strain SR58-5 which had been selected for 5 generations for sclerotinia resistance. The second resistant group (ranked "b" in Duncan's multiple range test) contained SR58-4 and SR58-3 which were selected for 4 and 3 generations, respectively. The survival percentage of the commercial cultivars except for Natsuwakaba was low. Strains selected for only one generation, SR58-1 and SLR61-1, did not show regrowth above $13 \%$ even after 3 months.

The relation between the number of generations in which selection was performed and the percentage of surviving plants of SR58 strains is shown in Fig. 1 and Fig. 2 , indicating clearly that the effectiveness of selection was low in the 1 st and 2 nd generations but that it increased from the 3 rd to 5 th generations.

Evaluation 2: Counts of plants displaying regrowth were made on January 27 and April 30. A significant difference was recognized in both observations (Table 3 ). Regrowth of the surviving plants was maximum in the investigation conducted on April 30. The strains of advanced generations which were selected from the 5 th

Table 1. Intensity of selection for $S$. trifoliorum in each generation

\begin{tabular}{llcccc}
\hline \hline $\begin{array}{c}\text { Generation } \\
\text { selection method }\end{array}$ & $\begin{array}{c}\text { No. of plants } \\
(\mathrm{M} . \text { lines) }\end{array}$ & $\begin{array}{c}\text { No. of selected } \\
\text { plants (M. lines) }\end{array}$ & $\begin{array}{c}\text { Selection } \\
\text { rate }^{\text {c) }}(\%)\end{array}$ & $\begin{array}{c}\text { Developed } \\
\text { strain }\end{array}$ \\
\hline 1 & Mass selection & 2,736 & 90 & 3.3 & SR58-1 \\
2 & Mass selection & 3,960 & 90 & 2.3 & SR58-2 \\
3 & Maternal line selection & $2,430(90)$ & $70(7)$ & 2.9 & SR58-3 \\
4 & Mass selection & 1,960 & 62 & 3.2 & SR58-4 \\
5 & Maternal line selection & $3,952(52)$ & $80(8)$ & 2.0 & SR58-5 \\
6 & Mass selection & 2,880 & 60 & 2.1 & SR58-6 \\
7 & Mass selection & 960 & 55 & 5.7 & SR58-7 \\
8 & Mass selection & 1,634 & 60 & 3.7 & SR58-8 \\
9 & Mass selection & 1,435 & 100 & 7.0 & SR58-9 \\
\hline
\end{tabular}

a): Generation in which selection was performed.

b): Maternal lines, within which individual plants were selected.

c): (No. of plants selected after observation of surviving plants/total number of plants in the field) $\times 100$. 
Table. 2 Differences in resistance among populations based on the percentage of plants which survived in plots inoculated with $S$. trifoliorum Evaluation 1 - selected strains vs. commercial varieties-

\begin{tabular}{|c|c|c|c|c|c|c|c|c|c|c|}
\hline \multirow{2}{*}{$\begin{array}{l}\text { Cultivar } \\
\text { or strain }\end{array}$} & \multicolumn{3}{|c|}{ Percentage of surviving plants } & & \multicolumn{6}{|c|}{$\begin{array}{c}\text { Multiple range } \\
\text { test* }\end{array}$} \\
\hline & Apr. 29 & May 14 & Jul. 6 & & & & & & & \\
\hline SR58-5 & 3.6 & 24.8 & 57.6 & $\mathrm{a}$ & & & & & & \\
\hline SR58-4 & 1.6 & 19.6 & 35.2 & & $\mathrm{~b}$ & & & & & \\
\hline SR58-3 & 2.4 & 15.6 & 31.2 & & $\mathrm{~b}$ & & & & & \\
\hline SHR61-2 & 2.4 & 9.6 & 20.8 & & & $\mathrm{c}$ & & & & \\
\hline SR58-2 & 0.8 & 8.0 & 17.6 & & & $\mathrm{c}$ & $\mathrm{d}$ & & & \\
\hline Natsuwakaba & 0.0 & 4.0 & 16.0 & & & $\mathrm{c}$ & $\mathrm{d}$ & $\mathrm{e}$ & & \\
\hline HR533-5 & 0.0 & 8.0 & 15.2 & & & $\mathrm{c}$ & $d$ & $\mathrm{e}$ & $\mathrm{f}$ & \\
\hline SR58-1 & 0.0 & 4.4 & 12.4 & & & $\mathrm{c}$ & d & $\mathrm{e}$ & $\mathrm{f}$ & $\mathrm{g}$ \\
\hline CR488-3 & 0.4 & 7.2 & 11.8 & & & & d & $\mathrm{e}$ & $\mathrm{f}$ & $\mathrm{g}$ \\
\hline SLR61-1 & 0.0 & 7.2 & 9.6 & & & & $d$ & $\mathrm{e}$ & $\mathrm{f}$ & $\mathrm{g}$ \\
\hline Williamsburg & 0.0 & 4.8 & 9.6 & & & & d & $\mathrm{e}$ & $\mathrm{f}$ & $\mathrm{g}$ \\
\hline Tachiwakaba & 0.0 & 4.0 & 7.2 & & & & & $\mathrm{e}$ & $\mathrm{f}$ & $\mathrm{g}$ \\
\hline Thor & 0.0 & 0.8 & 6.4 & & & & & $\mathrm{e}$ & $\mathrm{f}$ & $\mathrm{g}$ \\
\hline Aikei23 & 0.0 & 2.4 & 6.4 & & & & & $\mathrm{e}$ & $\mathrm{f}$ & $\mathrm{g}$ \\
\hline Vertace & 0.0 & 2.4 & 5.6 & & & & & & $\mathrm{f}$ & g \\
\hline Kitawakaba & 0.8 & 3.2 & 4.8 & & & & & & & $\mathrm{~g}$ \\
\hline du Puits & 0.0 & 6.4 & 4.8 & & & & & & & $\mathrm{~g}$ \\
\hline Orca & 0.0 & 2.4 & 4.0 & & & & & & & g \\
\hline CUF101 & 0.0 & 4.0 & 3.2 & & & & & & & g \\
\hline
\end{tabular}

*Duncan's multiple range test at $5 \%$ level.

to 9 th generations showed a high percentage of surviving plants, reflecting their superior resistance compared with Tachiwakaba and Natsuwakaba. The strain selected in the 6th generation, SR58-6 showed a 50.4\% survival rate which was $8 \%$ higher than that of SR58-5. Strain SR58-9

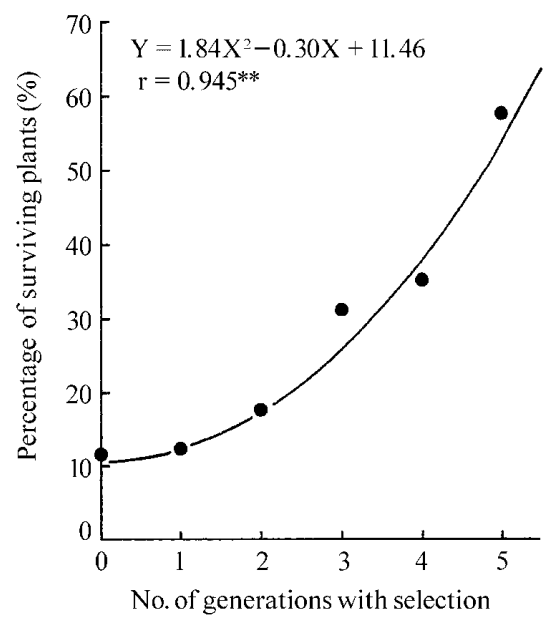

Fig. 1. Increase in resistance to Sclerotinia trifoliorum in relation to the number of generations with selection showed the highest survival rate of $62.9 \%$, although for SR58-7 and SR58-8 the gain in resistance was negligible. These results indicated that the increase of the resistance to SCR continued from the 6th generation up to the 9th generation. On the other hand, SLR61-2, SHR611-2,

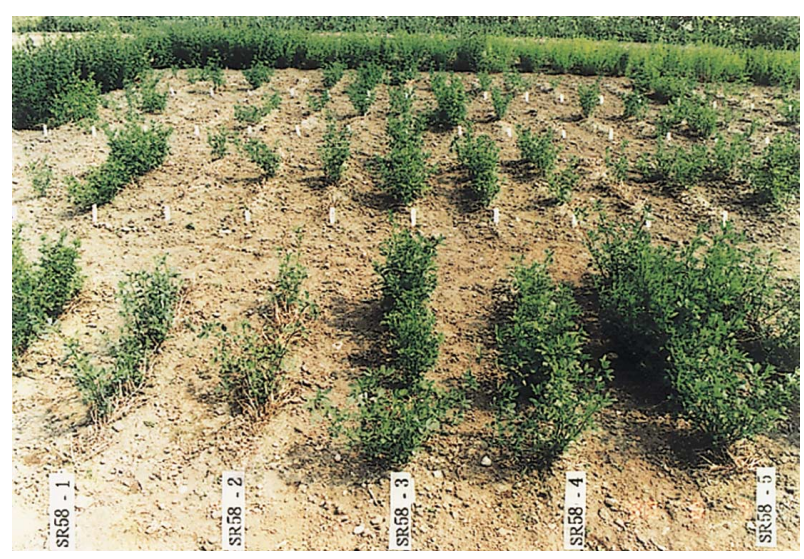

Fig. 2. Regrowth vigor of selected strains from 1st to 5 th generations 
Table 3. Differences in resistance among populations:

Evaluation 2 - advanced generation vs. control cultivars-

\begin{tabular}{|c|c|c|c|c|c|}
\hline $\begin{array}{l}\text { Cultivar } \\
\text { or strain }\end{array}$ & Jan. 27 & Apr. 30 & \multicolumn{2}{|c|}{$\begin{array}{l}\text { Multiple range } \\
\text { test* }\end{array}$} & $\begin{array}{c}\text { Fresh yield (May 30) } \\
\text { ratio to Tachiwakaba, \% }\end{array}$ \\
\hline SR58-9 & 41.5 & 62.9 & $\mathrm{a}$ & & 388 \\
\hline SR 58-8 & 34.8 & 51.3 & b & & 308 \\
\hline SR58-6 & 35.3 & 50.4 & $\mathrm{~b}$ & & 359 \\
\hline SR58-7 & 28.6 & 48.2 & $\mathrm{~b}$ & & 307 \\
\hline SR58-5 & 21.4 & 42.4 & $\mathrm{~b}$ & $\mathrm{c}$ & 251 \\
\hline SLR61-2 & 8.5 & 34.8 & & $\mathrm{c}$ & 135 \\
\hline SHR61-2 & 13.8 & 32.6 & & $\mathrm{c}$ & 190 \\
\hline Tachiwakaba & 8.0 & 23.2 & & d & 100 \\
\hline Natsuwakaba & 3.1 & 9.4 & & & 53 \\
\hline
\end{tabular}

*Duncan's multiple range test at $5 \%$ level.

SR92-1 which were selected in the 1st or 2nd generation showed a low percentage of surviving plants, and the results were similar to those in Evaluation 1.

Fresh yield of the first cutting in the SCR-test field was determined on May 30, and there were large differences among the strains and cultivars, as shown in the last column of Table 3. The yield gain of the selected strains beyond the 5 th generation was much higher than that of the commercial cultivars among them and SR58-9 showed the highest yield of $388 \%$ in relation to Tachiwakaba.

\section{Discussion}

Welty and Busbice ${ }^{15)}$ reported that the development of cultivars of forage legumes that were resistant to SCR had been difficult because of the non-specific character of the pathogen and the lack of a form of resistance easily identified by plant breeders. On the other hand, Elgin and Bayer ${ }^{1)}$ and Raynal $^{13)}$ recognized that some alfalfa and clover cultivars sustained less SCR damage than others. Pierson et al. ${ }^{11)}$ reported the effects of 2 cycles of selection for SCR in Ohio, USA. We confirmed the presence of cultivar differences in the resistance of alfalfa to SCR in the field by the developed artificial inoculation method, and found that cultivars of the Flamande type such as Lutece, Euver, and Everest were somewhat more resistant than the others ${ }^{8)}$. Furthermore, the selected strain obtained in our field at AARC displayed the highest resistance ${ }^{9}$. By repeated selection of surviving plants, the increase in resistance to SCR was clearly demonstrated. The strain SR58-5 selected for 5 generations was the most resistant among all the selected strains and commercial cultivars in Evaluation 1, and the strain SR58-9 selected for 9 generations was more resistant than SR58-
5 in Evaluation 2. The effectiveness of selection for the percentage of surviving plants increased gradually with the advance of generations. In order to combine the results of the evaluation in 2 different years, the heritability estimates of SCR resistance were calculated by Falconer's method ${ }^{3)}$. The heritability was estimated separately for the first 2 generations and subsequent 7 generations by fitting 2 linear regression lines. The response to selection was very low in the 1 st and 2 nd generations, and distinctly high from the 3rd to 9th generations. The regression coefficient of the selection response on the cumulative selection was designated as "realized heritability" by Falconer. In our results, the heritability of the SCR resistance was low $\left(\mathrm{h}^{2}=0.078\right)$ in the early generations but relatively high $\left(\mathrm{h}^{2}=0.368\right)$ in the subsequent generations (Fig. 3).

The theoretical studies on directional selection in

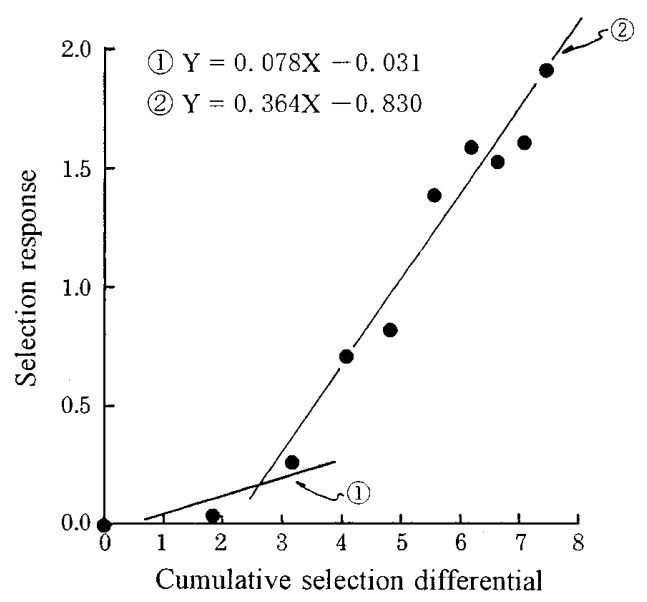

Fig. 3. Realized heritability by regression of response to selection on the cumulative selection differential 
autotetraploids ${ }^{5)}$ indicate that the rate of response is low in the early generations and increases as selection proceeds when a low frequency of desirable genotypes was assumed in the initial generation in which selection was performed, as the rate of changes in the gene frequency depends on the gene frequency in the population. Response to the selection increases with the repetition of the selection, which results in the increase of the frequency of useful genes. When these theoretical studies were applied to the change of heritability of the SCR resistance in our results, as the generation in which selection was performed advanced, it appeared that the frequency of occurrence of useful genes responsible for the SCR resistance was low in the original population. We were able to demonstrate that recurrent selection is effective for the accumulation of resistance genes with minor polygenic effect for resistance. A low response in the early generations but high in the subsequent generations was reported in the increase of verticillium resistance in alfalfa $^{14)}$, humid soil tolerance in alfalfa ${ }^{7)}$, low temperature germinability in colored guineagrass ${ }^{6}$ and sugar yield in sugar beet ${ }^{4}$. These reports present the results of selection when a new crop was exposed to new environmental conditions. In the case of plant breeding for the introduction of plant populations from foreign countries where very different climatic conditions prevail, this pattern of response to selection may be important. Change from the low frequency of useful genes to the accumulation of these genes, and reconstitution of useful genotypes may result in higher responses.

\section{Conclusion}

Evaluation of resistance of selected strains from the 1 st to 9 th generations was carried out in 2 groups. The effectiveness of selection was low in the 1st and 2nd generations, but strain SR58-5 selected for 5 generations was the most resistant among all the selected strains and commercial cultivars in Evaluation 1. The strain SR58-9 selected for 9 generations was more resistant than SR585 in Evaluation 2. In order to combine the results of the evaluation in the 2 experiments, the heritability estimates of the SCR resistance were calculated by Falconer's method (1960). The heritability was estimated separately for the first 2 generations and subsequent 7 generations by fitting 2 regression coefficients. The regression coefficient of the selection response on the cumulative selection was designated as "realized heritability" by Falconer. In our results, the heritability of the SCR resistance was low $\left(h^{2}=0.078\right)$ in the early generations but relatively high $\left(\mathrm{h}^{2}=0.368\right)$ in the subsequent generations.

\section{References}

1) Elgin, J. \& Beyer, E. H. (1968): Evaluation of selected alfalfa clones for resistance to Sclerotinia trifoliorum Eriks. Crop Sci., 8, 265-266.

2) Elgin, J., Welty, E. \& Gilchrist, D. B. (1988): Breeding for disease and resistance. In Alfalfa and alfalfa improvement. eds. Hanson, A. et al., American Society of Agronomy, Madison, 827-858.

3) Falconer, D. (1960): Threshold characters. In Introduction to quantitative genetics. Longman, New York, 270280.

4) Fujimoto, F. (1971): Studies on the maternal-line selection in sugar beet breeding. Bull.Sugar Beet Res., 10, 1136 [In Japanese with English summary].

5) Hill, R. (1971): Selection in Autotetraploids. Theor. Appl. Genet., 41, 181-186.

6) Kanbe, M. et al. (1981): Selection for higher germinability under low-temperature conditions in colored guineagrass. Res. Bull. Aichi Agric. Res. Ctr., 13, 108-115 [In Japanese with English summary].

7) Kanbe, M. et al. (1988): Alfalfa breeding for wet tolerance; Increase of adaptability to rainy region with the advance of selected generation. Res. Bull. Aichi Agric. Res. Ctr., 20, 136-143 [In Japanese with English summary].

8) Kanbe, M. et al. (1993): Development of inoculation method for testing field resistance to Sclerotinia crown and stem rot in alfalfa and evaluation of cultivars. Jpn. J. Breed. Sci., 43, 277-287.

9) Kanbe, M. et al. (1996): Growth conditions of alfalfa for screening of resistance to Sclerotinia trifoliorum and microscopic observations of infected tissues. Jpn. J Breed. Sci., 46, 261-268.

10) Nakane, A. \& Kaneda, T. (1987): Fungus disease. In New plant breeding technology. ed. Nakajima, T., Yokendo, Tokyo, 258-270 [In Japanese].

11) Pierson, P. et al. (1994): Selection for resistance to Sclerotinia crown and stem rot in the field and greenhouse. In Proc. 34th North Amer. Alfalfa Improvement Conf., 29.

12) Pratt, R. \& Rowe, D. (1996): Development and evaluation of Mississippi sclerotinia-resistance (MSR) alfalfa germplasm. In Proc. 36th North Amer. Alfalfa Improvement Conf., 14.

13) Raynal, G. (1981): Red clover and alfalfa crown rot caused by Sclerotinia trifoliorum Eriks. Agronomie, 1, 573-578.

14) Sjodin, J. (1990): Achievements in fodder crops breeding in nordic Europe Fodder crop breeding. In Proc. 16th meet. Fodder Crop Sect. Eucarpia, eds. Nijs A. P. M. \& Elgersma, A., Netherlands, 7-12.

15) Welty, R. \& Busbice, T. (1978): Field tolerance in alfalfa to Sclerotinia crown and stem rot. Crop Sci., 18, 508509 . 